\title{
Predicting growth and development of pigeonpea: flowering response to photoperiod
}

\author{
P.S. Carberry ${ }^{\mathrm{a}}$, R. Ranganathan ${ }^{\mathrm{b}, 1}$, L.J. Reddy ${ }^{\mathrm{b}}$, Y.S. Chauhan ${ }^{\mathrm{b}}$, M.J. Robertson ${ }^{\mathrm{c}, *}$

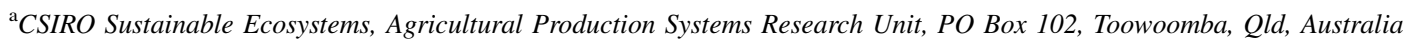 \\ ${ }^{\mathrm{b}}$ International Crops Research Institute for the Semi-Arid Tropics, Patancheru 502 324, India \\ ${ }^{\mathrm{c} C S I R O}$ Sustainable Ecosystems, Agricultural Production Systems Research Unit, 120 Meiers Rd, Indooroopilly, Qld 4067, Australia
}

Received 19 June 1998; received in revised form 10 October 2000; accepted 11 October 2000

\begin{abstract}
Data from sowing-date and other experiments conducted for nine cultivars at three locations ranging from $1^{\circ} 30^{\prime} \mathrm{S}$ to $27^{\circ} 15^{\prime} \mathrm{N}$ were analysed for photoperiod response. All cultivars were found to have a qualitative response to photoperiod. The results of the analysis show that cultivars previously reported to be "relatively insensitive" to photoperiod were, in fact, highly sensitive. Flowering in short-duration cultivars was delayed by up to a 100 days when daylength in the photoperiod-inductive phase exceeded a critical value. Medium- and long-duration cultivars delayed flowering by over 150 days in response to photoperiod. A model was able to predict this wide range in flowering dates. (C) 2001 Elsevier Science B.V. All rights reserved.
\end{abstract}

Keywords: Cajanus cajan; Pigeonpea; Phenology; Qualitative short-day response

\section{Introduction}

Pigeonpea (Cajanus cajan (L.) Millsp.), along with the majority of crop legumes of the tropics, is generally considered to have a quantitative short-day response (Summerfield and Roberts, 1985), i.e. one in which no further delay in flowering occurs above a ceiling photoperiod. Consistent with this, Akinola and Whiteman (1974), Sharma et al. (1981), Singh and Saxena (1981) and Saxena and Sharma (1990) in sowing studies in the field showed that the time from sowing to flowering was longest for sowing dates

\footnotetext{
* Corresponding author.

E-mail address: michael.robertson@tag.csiro.au (M.J. Robertson).

${ }^{1}$ Present address: KWS Saat AG, PO Box 1463, D 37555 Einbeck, Germany.
}

made prior to the summer solstice, shortening progressively as sowing dates were delayed into shortening days approaching the winter solstice. In contrast, Troedson et al. (1990) suggested that cv. UQ 1 had "possibly" a qualitative short-day response but provided no further supporting evidence. In a qualitative short-day response to photoperiod, floral initiation does not occur above a certain photoperiod and the plant initiates only when photoperiod falls below this photoperiod. Day-neutrality has also been reported by other researchers (Turnbull et al., 1981; Omanga et al., 1995).

In photoperiod-sensitive cultivars, a response is observed at photoperiods between a base $\left(P_{\mathrm{b}}\right)$ and critical $\left(P_{\mathrm{c}}\right)$ photoperiod during the photoperiodinductive phase of crop development (Major, 1980; Carberry et al., 1992). While others in the literature, 
notably Summerfield et al. (1995), have termed these cardinal points the "critical" and "ceiling" photoperiods respectively, in this paper the "critical photoperiod" is defined as that above which pigeonpea displays either a qualitative or quantitative shortday response.

From studies in controlled environments McPherson et al. (1985) showed that sensitivity of floral initiation to photoperiod in pigeonpea occurred when daylength exceeded $12 \mathrm{~h}$. This was observed by Turnbull (1986), who demonstrated that variation in daylength less than $12 \mathrm{~h}$ had little effect on the time to floral initiation if temperatures were held constant at $25 / 20^{\circ} \mathrm{C}$ day/night. When daylength was extended beyond $12 \mathrm{~h}$, however, there was a progressive delay in the time to initiation that was proportional to the increase in daylength in the medium- and late-maturity cultivars. Sharma et al. (1981) reported that $P_{\mathrm{c}}$ for most pigeonpea cultivars was $13 \mathrm{~h}$. There is little information from which the effects of temperature and photoperiod on flowering of pigeonpea can be predicted in a reliable manner (Lawn and Troedson, 1990; Troedson et al., 1990).

Differential genotypic sensitivity to a photoperiod has major implications for adaptation of pigeonpea with respect to latitude, altitude and season. As pigeonpea cultivation expands into new cropping systems (Laxman et al., 1996) and latitudes up to $45^{\circ} \mathrm{N}$ (Marsh, 1994; Davis et al., 1995) the quantification of environmental control of phenology becomes increasingly important. This paper applies a phenology model described in Carberry et al. (1992) to quantify the photothermal response of flowering in pigeonpea.

\section{Materials and methods}

\subsection{Data sources}

Data on the time to flowering of nine pigeonpea cultivars of different maturity types were available from trials conducted by the International Crops Research Institute for the Semi-Arid Tropics (ICRISAT) at Patancheru $\left(17^{\circ} 48^{\prime} \mathrm{N}\right)$ and Hisar $\left(27^{\circ} 15^{\prime} \mathrm{N}\right)$ in India. Data from a serially sown experiment at Katumani, Kenya $\left(1^{\circ} 30^{\prime} \mathrm{S}\right)$ (Omanga, 1994) were also included in the analysis. The details of these trials are summarised in Table 1.

\subsection{The phenological model}

The phenology model described in Carberry et al. (1992) to predict flowering in kenaf (Hibiscus cannabinus L.) was used here to examine the short-day photoperiod response of pigeonpea. The phenological development of a crop to flowering time can be described in terms of four stages: (i) emergence, (ii) the end of the basic vegetative or juvenile period (BVP), (iii) floral initiation and (iv) 50\% flowering. The duration of the period or phase at the end of which the crop progresses to the following stage is measured in thermal time.

The progression of the crop through the phases between stages (i) and (ii), and (iii) and (iv) is not affected by photoperiod and therefore, thermal time required for their completion is independent of the date of sowing. Following the BVP, the phase to floral initiation is sensitive to photoperiod. This photoperiod-induced phase (PIP) increases with photoperiod above a base photoperiod $P_{\mathrm{b}}$. For individual cultivars, the duration of PIP is thus dependent on daily photoperiod and photoperiod sensitivity $\left(P_{\mathrm{s}},{ }^{\circ} \mathrm{Cd} \mathrm{h}^{-1}\right)$. In quantitative (or facultative) short-day responses there is no further delay in floral initiation when photoperiod exceeds a critical photoperiod $P_{\mathrm{c}}$. In a qualitative (or obligate) short-day response to photoperiod, however, floral initiation does not occur above $P_{\mathrm{c}}$ and the plant initiates only when photoperiod falls below $P_{\mathrm{c}}$. After floral initiation, plants will flower after a set thermal time defining the duration of the floral development phase (FDP).

While there is no direct experimental evidence for the existence of a basic vegetative phase in pigeonpea, as could be demonstrated by photoperiod switching experiments (Ellis et al., 1992), it is here assumed that pigeonpea is similar to other warm-season legumes in which a BVP has been demonstrated (e.g. soybean, Ellis et al., 1992).

\subsection{Data analysis}

The phenology model described by Carberry et al. (1992) was attached to an optimization routine (NAG, 1983) which can minimize given objective functions using the simplex method. The model calculates daily thermal time accumulated during each phase and when thermal time sums are satisfied, development 
Table 1

Summary of datasets describing the time to flower of pigeonpea cultivars

\begin{tabular}{|c|c|c|c|c|}
\hline Location/type of experiment & Year(s) & Date(s) of sowing ${ }^{a}$ & Cultivars & Source of data \\
\hline \multicolumn{5}{|l|}{ (a) ICRISAT $\left(17^{\circ} 48^{\prime} \mathrm{N}\right)$} \\
\hline \multirow[t]{5}{*}{ Serial sowing } & 1974 & $31,46,80,112,141,173,203,234,265,294,325$ & Mukta, ST 1, T 21, UPAS 120 & ICRISAT (1975) \\
\hline & 1975 & 355 & HY 3C, ICP 7065, ST 1, T 21 & ICRISAT (1976) \\
\hline & 1981-1982 & $15,46,74,105,135,166,196,227,258,288,319,349$ & NP (WR) 15, C 11, UPAS 120 T 21 & ICRISAT (1982) \\
\hline & 1990-1991 & $105,135,166,196,227,258,288,319,349,15,46$ & ICPL 87 & Ranganathan et al. (2001) \\
\hline & 1992 & $171,207,239,270,299,330.360,28,58,86,135$ & ICPL 87 & Chauhan (unpubl.) \\
\hline \multirow[t]{22}{*}{ Misc. breeding and agronomy trials } & 1974 & 153 & HY 3C, ST 1 & ICRISAT (1975) \\
\hline & & $185,200,215,233$ & UPAS 120, T 21 & \\
\hline & & 177 & C $11, \mathrm{~T} 21, \mathrm{NP}(\mathrm{WR}) 15$ & \\
\hline & 1976 & 176 & ICP 7065, NP(WR) 15, C 11 & ICRISAT (1977) \\
\hline & 1977 & 181 & ICP 7065, NP(WR) 15, C 11, T 21 & ICRISAT (1978) \\
\hline & 1978 & 293 & Т 21 & ICRISAT (1979) \\
\hline & & 287 & T 21 & \\
\hline & & 319,349 & NP(WR) 15, ST 1 & \\
\hline & & 46 & NP(WR) 15, C 11, T 21, UPAS & \\
\hline & & 182 & 120 & \\
\hline & & $185,256,285$ & $\mathrm{NP}(\mathrm{WR}) 15, \mathrm{C} 11, \mathrm{~T} 21$ & \\
\hline & 1979 & 258 & ICP $7065, \mathrm{NP}(\mathrm{WR}) 15, \mathrm{C} 11, \mathrm{~T}$ & ICRISAT (1980) \\
\hline & & 286 & 21 & \\
\hline & & 287 & C 11, UPAS 120, T 21 & \\
\hline & & 317 & $\mathrm{C} 11$ & \\
\hline & & $178,180,181,194,303$ & $\mathrm{~T} 21$ & \\
\hline & & 193 & NP(WR) 15, C 11 ICP 7065, & \\
\hline & & 306 & ST 1, T 21 & \\
\hline & 1980 & & UPAS 120 & ICRISAT (1981) \\
\hline & & 319,349 & UPAS 120 & \\
\hline & & 46 & ICP $7065, \mathrm{NP}(\mathrm{WR}) 15, \mathrm{C} 11, \mathrm{~T}$ & \\
\hline & & 258,317 & 21 & \\
\hline
\end{tabular}


Table 1 (Continued)

\begin{tabular}{|c|c|c|c|c|}
\hline Location/type of experiment & Year(s) & Date(s) of sowing ${ }^{\mathrm{a}}$ & Cultivars & Source of data \\
\hline \multicolumn{5}{|l|}{ (b) Hissar $\left(27^{\circ} 15^{\prime} \mathrm{N}\right)$} \\
\hline \multirow[t]{9}{*}{ Misc. breeding and agronomy trials } & 1979 & 193 & $\mathrm{~T} 21$ & \multirow[t]{9}{*}{ ICRISAT (unpubl.) } \\
\hline & 1980 & 112 & $\mathrm{~T} 21$ & \\
\hline & & 175 & UPAS 120 & \\
\hline & & 179,180 & ICPL 87, UPAS 120, T 21 & \\
\hline & 1981 & 105 & ICPL 87, T 21 & \\
\hline & & 174 & ICPL 87, UPAS 120, T 21 & \\
\hline & 1983 & $91,173,202$ & ICPL 87, UPAS 120, T 21 & \\
\hline & & 177 & UPAS 120 & \\
\hline & 1986 & 206 & UPAS 120 & \\
\hline \multicolumn{5}{|l|}{ (c) Katumani $\left(1^{\circ} 30^{\prime} S\right)$} \\
\hline Serial sowing & $1991-1992$ & $97,127,158,188,219,250,280,312,341,7,38,66$ & C 11, UPAS 120, T 21, ICPL 87 & Omanga (1994) \\
\hline
\end{tabular}

${ }^{a}$ Time of sowing are given as day of year (January 1 equals day 1). Note: (i) in serial sowing experiments some cultivars did not flower for every sowing, (ii) in miscellaneous breeding and agronomy trials, on some days there were two sowings of a cultivar. 
progresses to the next phase, culminating in flowering. Parameters for the model are derived from an iterative optimization procedure aimed at minimizing the sums of squares of the difference between the predicted and measured number of days from sowing to flowering. Model parameters are the thermal time targets for the various phases and the cardinal temperature and photoperiod values used to calculate the photothermal response. These parameters can either be estimated through optimisation or set to fixed values. This approach has been successfully applied to modelling phenology and growth of a range of crops (Holzworth and Hammer, 1992; Jones and Carberry, 1994). This approach does not use the traditional calibration validation two-step process of model development and testing, but rather utilises all the data in the derivation of the model parameters.

The optimisation model was run for each of the nine cultivars specified in Table 1. Cardinal temperatures for development were estimated from published germination and emergence studies. This approach was taken because their conservative nature has been demonstrated with a number of species. Ong and Monteith (1985), e.g. found that the cardinal temperatures for pearl millet were similar for a wide range of processes including germination, leaf appearance, panicle initiation, flowering and the duration of grain-filling. Carberry and Abrecht (1990) determined cardinal temperatures for hypocotyl elongation of kenaf and argued that these values could be used in determining thermal time for post-emergent development of kenaf.

For pigeonpea, Odongo et al. (1991) conducted a germination study on a thermogradient plate using 10 cultivars. They reported a mean base temperature $\left(T_{\mathrm{b}}\right)$ of $9.9^{\circ} \mathrm{C}$ (range $6.7-12.4$ ), an optimum $\left(T_{\mathrm{o}}\right)$ of $32.0^{\circ} \mathrm{C}$ (range $26.2-36^{\circ} \mathrm{C}$ ) and a ceiling temperature $\left(T_{\mathrm{c}}\right)$ of $45^{\circ} \mathrm{C}$ (range $43.4-46^{\circ} \mathrm{C}$ ). The substantial variation in cardinal temperatures observed was related to the origin of the cultivars. For example, cultivars adapted to cool conditions in northern India tended to have a lower $T_{\mathrm{b}}$. Based on a study of three cultivars, de Jabrun et al. (1981) reported a mean optimum soil temperature of $32.5^{\circ} \mathrm{C}$ (range $29-36^{\circ} \mathrm{C}$ ) and a base temperature (of the soil) of $7.1^{\circ} \mathrm{C}$ for germination. They also observed optimum soil temperature for emergence or radicle-hypocotyl elongation, measured 2 days after germination, to be $32.5^{\circ} \mathrm{C}$ (range $29-36^{\circ} \mathrm{C}$ ). Angus et al. (1981) examined the thermal time and base temperature for emergence in pigeonpea, with 16 sowings and six cultivars, with air temperatures varying from 10 to $29^{\circ} \mathrm{C}$. The base temperature was calculated as $12.8 \pm 0.14^{\circ} \mathrm{C}$ and the thermal time as $58.2 \pm 2.87^{\circ} \mathrm{Cd}$. Temperature of irrigated soil can be $2-3^{\circ} \mathrm{C}$ below ambient air temperatures (Chauhan et al., 1988) and may explain overestimation of the base temperature in Angus et al. (1981). Studies on stand establishment (ICRISAT, 1978) showed that on a vertisol, thermal time to $50 \%$ emergence (using $T_{\mathrm{b}}=10^{\circ} \mathrm{C}$ ) for a range of seed sizes was measured as $61.3^{\circ} \mathrm{Cd}$ to depths of $10 \mathrm{~cm}$. For seeds at $3 \mathrm{~cm}$ depth in pots, in a controlled environment chamber $\left(25^{\circ} \mathrm{C}\right)$, the thermal time to $50 \%$ emergence $\left(T_{\mathrm{b}}=10^{\circ} \mathrm{C}\right)$ was 51.6 and $58.8^{\circ} \mathrm{Cd}$ for cultivars ICPL 87 and ICP 1-6, respectively (D.J. Flower, unpublished data).

In summary, from these studies parameter values for thermal time to emergence and $T_{\mathrm{b}}$ were fixed at $60^{\circ} \mathrm{Cd}$ and $10^{\circ} \mathrm{C}$, respectively. However, the analysis suggested that the estimate of $T_{\mathrm{o}}$ required further clarification. In order to confirm these cardinal temperatures, the model was first optimised for $T_{\mathrm{o}}$ and $T_{\mathrm{m}}$ as well as for the thermal time targets for BVP and FDP, for the cultivar's photoperiod sensitivity $P_{\mathrm{s}}$ and for the cardinal photoperiods $P_{\mathrm{b}}$ and $P_{\mathrm{c}}$. As a second step, values for $T_{\mathrm{o}}$ and $T_{\mathrm{m}}$ were fixed to the values determined by the previous optimisation and the remaining parameters were estimated to provide the best prediction of time to flowering for each cultivar. Thermal time was calculated with the algorithms used by Jones et al. (1986), which divide each day into eight 3-h time periods on the basis of daily inputs of maximum and minimum temperatures. The photoperiod for each day was calculated from latitude and calendar day and included allowance for civil twilight when solar angle $\geq-6^{\circ}$ (Goodspeed, 1975).

The accuracy of the prediction of time to flowering was assessed using the coefficient of determination $\left(R^{2}\right)$ derived from the regression of observed and predicted days to flower, and the root mean square deviation (RMSD) which represents a mean weighted difference between predicted and observed data. RMSD is calculated as

$\operatorname{RMSD}=\left[\frac{\sum(O-P)^{2}}{n}\right]^{0.5}$ 
where $O$ and $P$ are the paired observed and predicted time to flower and $n$ is the number of observations.

\section{Results}

\subsection{A qualitative photoperiod response}

A strong qualitative photoperiod response will be evident in serial sowings of a cultivar if photoperiod changes over the response range. This was clearly the case with most of the serial sowing experiments of pigeonpea detailed in Table 1. Take for example the data for cultivar ICPL87 sown in 1990/1991 (Table 2). Time to flowering took between 50 and 74 days after sowing for sowing dates between June 1990 and January 1991. However, the February 1991 sowing flowered after 169 days - a 30-day delay in sowing resulted in an extra 119 days to reach first flower compared to the previous sowing date. Subsequent sowing dates took progressively shorter times to reach flowering.

In a qualitative short-day response, plants flower only when photoperiod is below a critical value. In the February 1991 sowing (Table 2), plants flowered on the 15 August 1991 (day 225). Plants sown at the subsequent three dates, March-May, also flowered on or very close to this same date. Clearly, this cultivar when sown at these times reached the BVP when photoperiods exceeded $P_{\mathrm{c}}$ and thus remained unresponsive until photoperiod fell below $P_{\mathrm{c}}$. Because plants in all four sowing dates experienced inductive photoperiods at the same time, when $P<P_{\mathrm{c}}$, they all reached flowering at the same time.

Fig. 1 presents days to flowering plotted against date of sowing for the nine cultivars in Table 1 . The qualitative response described above is evident in all cultivars, markedly so in the medium-duration cultivars (C 11, ST 1, Mukta) and long-duration cultivars (HY 3C, ICP 7065, NP (WR) 15). In the short-duration types (ICPL 87, T 21, UPAS 120), only a small number of observations appear influenced by a qualitative photoperiod response, although the data for ICPL 87 in Table 2 suggest that in at least four sowing dates plants were delayed by photoperiods greater than $P_{\mathrm{c}}$. Clearly, there is strong evidence from these data that pigeonpea displays a qualitative short-day response.

\subsection{Parameter values}

When the parameters $T_{\mathrm{o}}$ and $T_{\mathrm{m}}$ were initially included in the optimisation, estimated values ranged from 22 to $25^{\circ} \mathrm{C}$ for $T_{\mathrm{o}}$ and from 35 to $60^{\circ} \mathrm{C}$ for $T_{\mathrm{m}}$ for most of the nine cultivars studied. For several cultivars, the optimisation failed to achieve adequate solutions for $T_{\mathrm{o}}$ and $T_{\mathrm{m}}$. For those cultivars for which adequate solutions were found, the average value for $T_{\mathrm{o}}$ was $24^{\circ} \mathrm{C}$ and for $T_{\mathrm{m}}$ was $45^{\circ} \mathrm{C}$. In subsequent optimisations, values for $T_{\mathrm{b}}, T_{\mathrm{o}}$ and $T_{\mathrm{m}}$ were fixed at 10,24 and $45^{\circ} \mathrm{C}$, respectively.

The fitted parameters for the nine cultivars are given in Table 3 and the accuracy of the fitted model is

Table 2

Flowering time for short-duration pigeonpea cultivar ICPL87 grown in a serial sowing trial at ICRISAT in 1990-1991 (Table 1)

\begin{tabular}{|c|c|c|c|c|}
\hline \multirow[t]{2}{*}{ No. } & \multicolumn{2}{|l|}{ Sowing } & \multicolumn{2}{|c|}{ 50\% Flowering } \\
\hline & Date & Day of year & Day of year & Days after sowing \\
\hline 1 & 20 June 1990 & 171 & 245 & 74 \\
\hline 2 & 26 July & 207 & 273 & 66 \\
\hline 3 & 27 August & 239 & 302 & 63 \\
\hline 4 & 27 September & 270 & 330 & 60 \\
\hline 5 & 26 October & 299 & 355 & 56 \\
\hline 6 & 26 November & 330 & 22 & 57 \\
\hline 7 & 26 December & 360 & 50 & 55 \\
\hline 8 & 28 January 1991 & 28 & 78 & 50 \\
\hline 9 & 27 February & 58 & 227 & 169 \\
\hline 10 & 27 March & 86 & 225 & 139 \\
\hline 11 & 15 May & 135 & 229 & 94 \\
\hline 12 & 27 May & 147 & 229 & 82 \\
\hline
\end{tabular}


ICPL 87

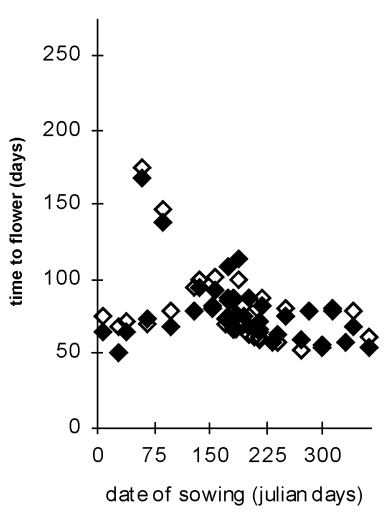

C 11

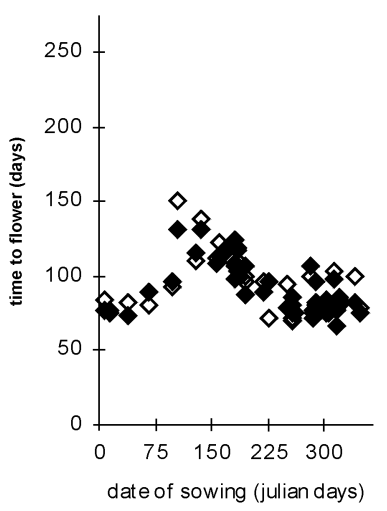

HY 3C

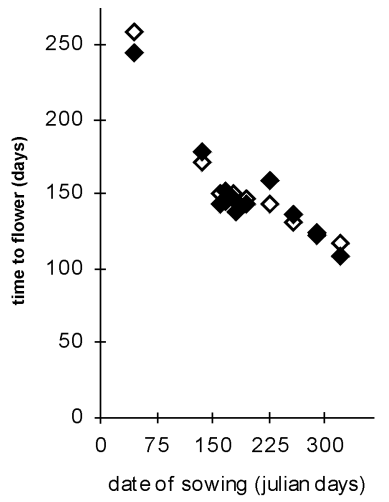

T 21

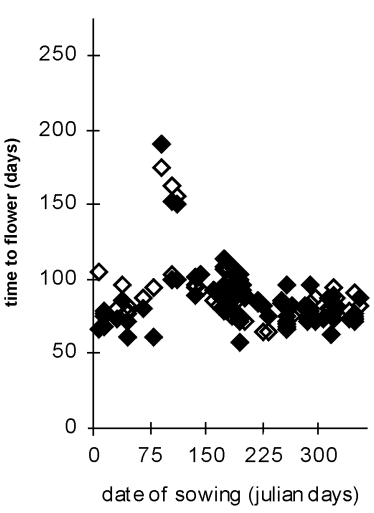

ST 1

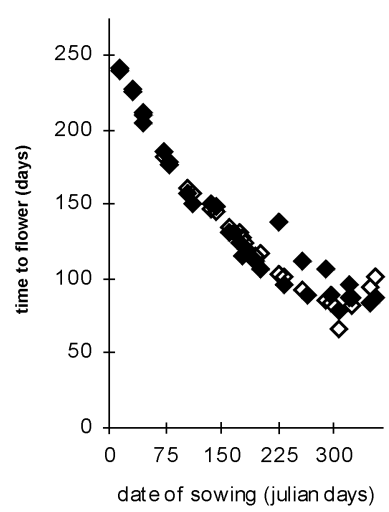

ICP 7065

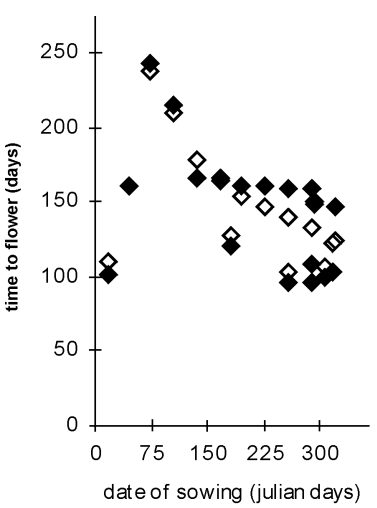

UPAS 120

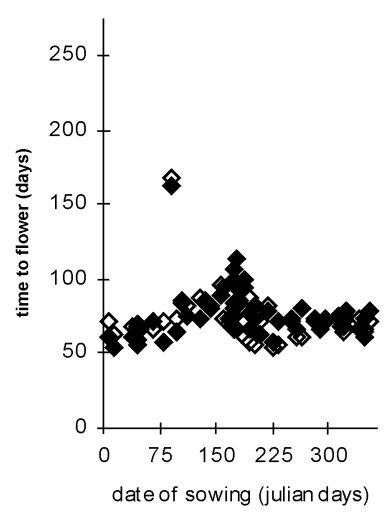

Mukta

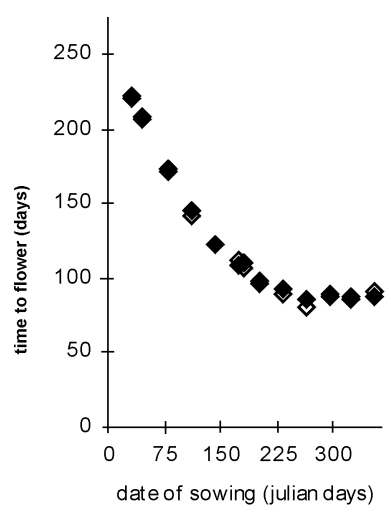

NP (WR) 15

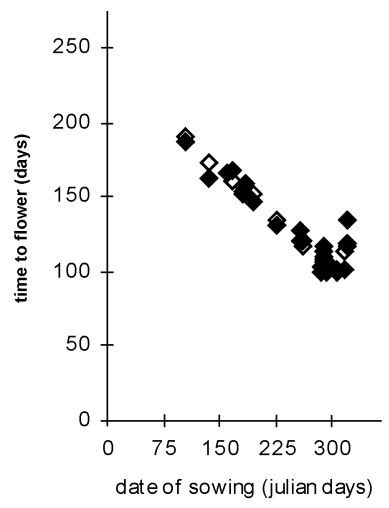

Fig. 1. The effect of daylength in delaying time to flower in crops sown at different times in the year. Solid symbols represent observed data, hollow symbols are predicted time to flower. 
Table 3

Parameters of the phenology model

\begin{tabular}{|c|c|c|c|c|c|c|}
\hline Duration type & Cultivar & $\mathrm{BVP}\left({ }^{\circ} \mathrm{Cd}\right)$ & $P_{\mathrm{s}}\left({ }^{\circ} \mathrm{Cd} \mathrm{h}^{-1}\right)$ & $\mathrm{FDP}\left({ }^{\circ} \mathrm{Cd}\right)$ & $P_{\mathrm{b}}(\mathrm{h})$ & $P_{\mathrm{c}}(\mathrm{h})$ \\
\hline \multirow[t]{4}{*}{ Short } & ICPL 87 & 389 & 162 & 125 & 12.05 & 13.55 \\
\hline & Т 21 & 289 & 296 & 420 & 13.11 & 14.14 \\
\hline & UPAS 120 & 227 & 532 & 356 & 13.50 & 14.05 \\
\hline & Average & 302 & 330 & 300 & 12.89 & 13.91 \\
\hline \multirow[t]{4}{*}{ Medium } & C 11 & 405 & 1028 & 350 & 12.87 & 14.73 \\
\hline & ST 1 & 304 & 668 & 298 & 11.82 & 13.41 \\
\hline & Mukta & 409 & 444 & 307 & 12.08 & 13.49 \\
\hline & Average & 373 & 713 & 318 & 12.26 & 13.88 \\
\hline \multirow[t]{4}{*}{ Medium/long } & HY 3C & 183 & 747 & 507 & 11.55 & 12.86 \\
\hline & ICP 7065 & 337 & 558 & 603 & 11.75 & 13.38 \\
\hline & NP(WR) 15 & 460 & 768 & 485 & 11.80 & 13.05 \\
\hline & Average & 327 & 691 & 532 & 11.70 & 13.10 \\
\hline
\end{tabular}

presented in Table 4. Predicted days to flowering for each of the nine cultivars is also included with observed data in Fig. 1, plotted against date of sowing. Generally, the qualitative short-day model simulated well the often large changes in time to flowering for all cultivars. The model was able to predict days to flowering ranging between 50 and 250 days as well as discern differences between locations. For example, for cultivar ICPL 87 sown in February, the model accurately predicted a 100 -day difference in time to flowering between ICRISAT, India, and Katumani, Kenya. Over all cultivars, locations and sowing dates $(n=308)$, the model accounted for $92 \%$ of the observed variation in time to flowering with a RMSD of 10.45 days, representing less than $11 \%$ of the mean time to flowering (Fig. 2, Table 3).
There was considerable variation in fitted parameter values across cultivars, and even within duration types (Table 3). Apart from a clearly longer floral development period (FDP) in the long duration types, the length of the BVP and FDP displayed relatively small variation among duration types. When the parameter value of FDP was fixed to an overall average value and the remaining parameters re-optimised, prediction accuracies and fitted parameter values altered only slightly for most cultivars (data not presented). However, for BVP, a similar analysis resulted in significant changes in predictions.

Most genotypic variation in the duration of the three phases appeared to occur in the PIP, where $P_{\mathrm{s}}$ ranged between 162 and $1028^{\circ} \mathrm{Cd} \mathrm{h}^{-1}$. The model suggested that all the cultivars were highly photoperiod-

Table 4

The slopes and coefficients of determination of the linear regressions of predicted and observed days to flower

\begin{tabular}{|c|c|c|c|c|c|c|c|c|}
\hline Duration type & Cultivar & $n$ & Intercept & S.E. & Slope & S.E. & $R^{2}$ & RMSD (days) \\
\hline \multirow[t]{3}{*}{ Short } & ICPL 87 & 38 & 4.2 & 5.77 & 0.96 & 0.07 & 0.83 & 9.78 \\
\hline & T 21 & 74 & 19.44 & 6.14 & 0.77 & 0.07 & 0.63 & 12.61 \\
\hline & UPAS 120 & 54 & 10.26 & 6.21 & 0.86 & 0.08 & 0.7 & 10.04 \\
\hline \multirow[t]{3}{*}{ Medium } & C 11 & 47 & 9.56 & 7.9 & 0.89 & 0.08 & 0.71 & 10.15 \\
\hline & ST 1 & 29 & -2.65 & 6.5 & 1.02 & 0.05 & 0.95 & 10.62 \\
\hline & Mukta & 13 & -2.77 & 2.53 & 1.02 & 0.02 & 0.99 & 3.03 \\
\hline \multirow[t]{3}{*}{ Medium/long } & HY 3C & 11 & 6.75 & 12.65 & 1.05 & 0.08 & 0.95 & 8.44 \\
\hline & ICP 7065 & 18 & 20.53 & 10.13 & 0.85 & 0.07 & 0.91 & 12.4 \\
\hline & NP(WR) 15 & 24 & 3.93 & 6.73 & 0.97 & 0.05 & 0.94 & 6.36 \\
\hline Overall & & 308 & 3.29 & 1.72 & 0.96 & 0.02 & 0.92 & 10.45 \\
\hline
\end{tabular}




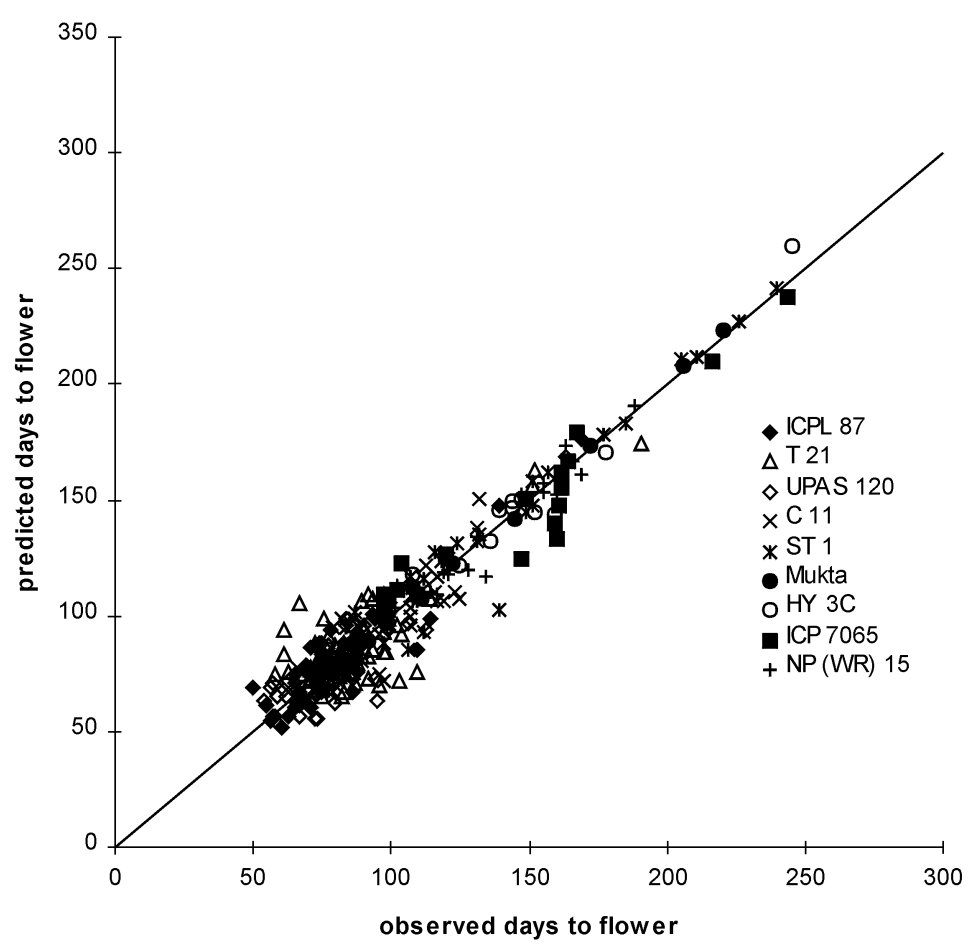

Fig. 2. Observed and predicted days to flower of nine pigeonpea cultivars.

sensitive, although the short-duration types are relatively less so compared to the medium- and longduration types. While there were exceptions for individual cultivars, values for $P_{\mathrm{b}}$ and $P_{\mathrm{c}}$ declined as duration type moved to longer maturity. So, while the short-duration types were photoperiod-sensitive, they express this response only in relatively longer photoperiod regimes at higher latitudes. In contrast, the medium- and long-duration cultivars are more demonstratively photoperiod-sensitive, having high values for $P_{\mathrm{s}}$ and lower values for $P_{\mathrm{b}}$ and $P_{\mathrm{c}}$. This relative photoperiod sensitivity between duration types, in both the duration of PIP and in the qualitative response, is evident in the observed data presented in Fig. 1.

\section{Discussion}

The major finding of this study is the new evidence that pigeonpea is highly photoperiod-sensitive and that it responds as a qualitative short-day plant irre- spective of duration class. The qualitative response, i.e. one in which flowering does not occur when photoperiod exceeds a critical value, was strongly evident for all cultivars in this study (Fig. 1). This outcome contrasts with the conclusions of Summerfield and Roberts (1985) and others who had classified pigeonpea as having a quantitative short-day response, i.e. one in which no further delay in flowering occurs above a critical (or, in their terms, ceiling) photoperiod. Also of significance, is the finding that shortduration pigeonpea is photoperiod-sensitive which also conflicts with the common classification for pigeonpea (Sharma and Green, 1980).

The reasons for such big discrepancies between analyses of the photoperiod response in pigeonpea needs to be explored. Obviously, where previous studies were conducted under short photoperiods (e.g. Omanga et al., 1995), no photoperiod response could be determined. Likewise, discovery of a qualitative response requires pigeonpea to be grown under long days ( $>13-13.5 \mathrm{~h}$ ) for a significant duration when the plants are within their PIP. Thirdly, the pigeonpea 
cultivars being studied need to be photoperiod-sensitive and, while all were so in this study, genotypic variation was evident. However, the fact that much of the data used in this study were collected in experiments undertaken up to 23 years ago suggests that lack of appropriate data did not restrict correct analysis of pigeonpea's photoperiod response.

A final key requirement for accurate determination of the photoperiod response of crops is an analytical framework which incorporates the potential crop response to photoperiod. The model utilised here for pigeonpea was able to capture the qualitative photoperiod response that was clearly evident in the data. However, one limitation of this modelling approach is its heavy reliance on use of optimisation to fit parameter values. Such iterative optimisation approaches rely both on the fitted model being physiologically sound and appropriate to the data and an assurance that inappropriate solutions are recognised and discarded. The optimisation approach used here estimated the thermal time requirement for floral initiation, yet no measurements of when this intermediate stage occurred were included in the data in Table 1 . The model predicted time to floral initiation based on parameter values that best describe time to flowering over a range of data. While the phenological model has previously proven appropriate for several other crops (Major, 1980; Carberry et al., 1992), confirmation of when intermediate stages occur in pigeonpea is required for validation of the model and parameter values estimated in these analyses. At this stage, the main case for supporting this model and optimisation approach relies on the good predictions of time to flowering across a range of cultivars, locations and times of sowing (Fig. 2).

Given this case of pigeonpea and previous work on kenaf (Carberry et al., 1992), there is a need to question the multiple regression approach used by Summerfield, Lawn and others (Summerfield et al., 1995) as providing appropriate representations of the phenological response of crops. Those regression approaches do not acknowledge that crops may respond to photoperiod for only a portion of their lifecycle. By using mean temperature and photoperiod over the whole period as independent predictors, they fail to utilise the total information contained in the daily climate record, nor are they influenced by crops developing under either lengthening or shortening daylengths. Finally, the regression model is unable to describe a qualitative photoperiod response and associated phenomena such as reversion (partial flowering followed by reversion to vegetative development) (Carberry et al., 1992).

Pigeonpea cultivars are classified into duration types based on time to flowering when grown during the monsoon season at two sites in India (Gupta et al., 1989). The limitations of this classification system are evident when "short" duration types can take between 150 and 200 days to flowering (Fig. 1) when grown at other locations and times of year. An improved system of classification of maturity type could be based on quantifying the phenological parameters of cultivars as given in Table 3. The analyses in this paper indicate that short-duration types tend to have lower values for photoperiod sensitivity $\left(P_{\mathrm{s}}\right)$ and higher values for $P_{\mathrm{b}}$ and $P_{\mathrm{c}}$ compared to longer-duration types. However, time to flowering is influenced by the combination of these responses, so that the effect of high $P_{\mathrm{s}}$ can be offset by high $P_{\mathrm{b}}$ and consequently a relatively shortduration to flowering under most conditions (e.g. UPAS 120).

The optimised parameters suggested that, unlike other tropical legume crops where optimum temperatures for flowering are in the range $28-32^{\circ} \mathrm{C}$ (Roberts and Summerfield, 1987), pigeonpea appears to have an optimum temperature between 20 and $24^{\circ} \mathrm{C}$. There is some experimental evidence to support this. From controlled environment studies, Turnbull (1986) reported for two short-duration cultivars (QPL-2 and QPL-3) as photoperiod-insensitive, the rate of progress to flower bud initiation in Turnbull's data was highest at a mean temperature around $20^{\circ} \mathrm{C}$. Omanga (1994) measured days to floral bud initiation for short-duration pigeonpea at Katumani, Kenya $\left(1^{\circ} 30^{\prime} \mathrm{S}\right)$ where daylength varies little (12.78$12.97 \mathrm{~h}$ including civil twilight) over the year. Floral initiation was quickest at $21.6^{\circ} \mathrm{C}$. McPherson et al. (1985) concluded from their studies with pigeonpea cultivars from contrasting maturity groups that the optimum temperature for floral initiation was between 20 and $24^{\circ} \mathrm{C}$. Interestingly, pigeonpea appears to have a set of cardinal temperatures for floral initiation and flowering $\left(10,22\right.$ and $\left.35^{\circ} \mathrm{C}\right)$ different from that for germination and emergence, and leaf appearance (Ranganathan et al., 2001) (10, 32 and $\left.45^{\circ} \mathrm{C}\right)$. This range is $6-8^{\circ} \mathrm{C}$ cooler compared to many other tropical 
legumes (Roberts and Summerfield, 1987). There are no instances cited in the literature where optimum temperatures for floral initiation/flowering and other developmental processes differ by as much as $9-10^{\circ} \mathrm{C}$.

\section{Conclusions}

Measured data and modelling analyses show that pigeonpea can be classified as a qualitative short-day plant, in which flowering does not occur at photoperiods greater than a critical value. This finding corrects a previous misinterpretation of pigeonpea's photoperiod response.

\section{Acknowledgements}

The authors would like to thank Dr. C. Johansen and staff of the Agronomy Division, and Dr. R.K. Kapoor and others in Genetic Enhancement Division at ICRISAT for their cooperation. The assistance of Anil Verma in processing data is appreciated. This research was supported by funding from the Australian Centre for International Agricultural Research.

\section{References}

Akinola, J.O., Whiteman, P.C., 1974. Agronomic studies on pigeon pea (Cajanus cajan (L.) Millsp.). I. Field responses to sowing time. Aust. J. Agric. Sci. 26, 43-56.

Angus, J.F., Cunningham, R.B., Moncur, M.W., MacKenzie, D.H., 1981. Phasic development in field crops. I. Thermal response in the seedling phase. Field Crops Res. 3, 365-378.

Carberry, P.S., Abrecht, D.G., 1990. Germination and elongation of the hypocotyl and radicle of kenaf (Hibiscus cannabinus L.) in response to temperature. Field Crops Res. 24, 227-240.

Carberry, P.S., Muchow, R.C., Williams, R., Sturz, J.D., McCown, R.L., 1992. A simulation model of kenaf for assisting fibre industry planning in Northern Australia. 1. General introduction and phenological model. Aust. J. Agric. Res. 43, 15011513.

Chauhan, Y.S., Nene, Y.L., Johansen, C., Haware, M.P., Saxena, N.P., Sardar Singh, Sharma, S.B., Sahrawat, K.L., Burford, J.R., Rupela, O.P., Kumar Rao, J.V.D.K., Sitananthan, S., 1988. Effects of soil solarization on pigeonpea and chickpea. Res. Bull. No. 11. ICRISAT, Patancheru, AP, India.

Davis, D.W., Gingera, G.R., Sauter, K.J., 1995. MN 1, MN 5 and MN 8 early duration pigeonpea lines. Intl. Chickpea Pigeonpea Newslett. 2, 57-58.
Ellis, R.H., Collinson, S.T., Hudson, D., Patefield, W.M., 1992. The analysis of reciprocal transfer experiments to estimate the durations of the photoperiod-sensitive and photoperiod insensitive phases of plant development: an example in soybean. Ann. Bot. 70, 87-92.

Goodspeed, M.J., 1975. Computer routines for solar position, daylength and related qualities. Tech. Mem. No. 75/11. CSIRO, Division of Land Use Research, Canberra, Australia.

Gupta, S.C., Johansen, C., Laxman, S., 1989. Uniformity of nomenclature in short-duration pigeonpea. Int. Pigeonpea Newslett. 10, 3-6.

Holzworth, D.P., Hammer, G.L., 1992. DEVEL: a crop development modelling tool. Queensland Department of Primary Industries, Brisbane. Bulletin QB92001, 31 pp.

ICRISAT, 1975. ICRISAT Annual Report 1974-1975. Hyderabad, India.

ICRISAT, 1976. ICRISAT Annual Report 1975-1976. Hyderabad, India.

ICRISAT, 1977. ICRISAT Annual Report 1976-1977. Hyderabad, India.

ICRISAT, 1978. ICRISAT Annual Report 1977-1978. Hyderabad, India.

ICRISAT, 1979. ICRISAT Annual Report 1978-1979. Hyderabad, India.

ICRISAT, 1980. ICRISAT Annual Report 1979-1980. Hyderabad, India.

ICRISAT, 1981. ICRISAT Annual Report 1980-1981. Hyderabad, India.

ICRISAT, 1982. ICRISAT Annual Report 1981-1982. Hyderabad, India.

de Jabrun, P.L.M., Byth, D.E., Wallis, E.S., 1981. Imbibition by and effects of temperature on germination of mature seed of pigeonpea. In: Proceedings of the International Workshop on Pigeonpeas, Vol. 2, December 15-19, 1980. ICRISAT Center, India. ICRISAT, Patancheru, AP, India, pp. 181-187.

Jones, P.N., Carberry, P.S., 1994. A technique to develop and validate simulation models. Agric. Syst. 46, 427-442.

Jones, C.A., Ritchie, J.T., Kiniry, J.R., Godwin, D.C., 1986. Subroutine structure. In: Jones, C.A., Kiniry, J.R. (Eds.), CERESMaize: A Simulation Model of Maize Growth and Development. Texas A \& M University Press, College Station, TX, pp. 49-111.

Lawn, R.J., Troedson, R.J., 1990. Pigeonpea: physiology of yield formation. In: Nene, Y.L., Hall, S.D., Sheila, V.K. (Eds.), The Pigeonpea. CAB International, Wallingford, pp. 179-208.

Laxman, S., Chauhan, Y.S., Johansen, C., Singh, S.P. (Eds.), 1996. Prospects for Growing Extra-short Duration Pigeonpea in Rotation with Winter Crops. Proceedings of the Iari/Icrisat Workshop and Monitoring Tour, October 16-18, 1995, New Delhi, India. IARI and ICRISAT, New Delhi 110 012, and Patancheru 502 324, 132 pp.

Major, D.J., 1980. Photoperiod response characteristics controlling flowering of nine crop species. Can. J. Plant Sci. 60, 777-784.

Marsh, L., 1994. Planting date effects on early maturing pigeonpea in a short season environment. HorTech. 4, 379-382.

McPherson, H.G., Warrington, I.J., Turnbull, H.L., 1985. The effects of temperature and daylength on the rate of development of pigeonpea. Ann. Bot. 56, 597-611. 
Numerical Algorithms Group (NAG) (1983). The Nag Fortran PC50 Library Handbook - Release 1.

Odongo, J.C.W., Sharma, M.M., Ong, C.K., 1991. Influence of temperature on seed germination of pigeonpea genotypes. In: Sen, D.N., Mohammed, S. (Eds.), Proceedings of the International Seed Symposium 1990, pp. 293-298.

Omanga, P.A., 1994. Measurement and prediction of flowering in pigeonpea (Cajanus cajan). Ph.D. Thesis. University of Reading, UK.

Omanga, P.A., Summerfield, R.J., Qi, A., 1995. Flowering of pigeonpea (Cajanus cajan) in Kenya: responses of early maturing genotypes to location and date of sowing. Field Crops Res. 41, 25-34.

Ong, C.K., Monteith, J.L., 1985. Response of pearl millet to light and temperature. Field Crops Res. 11, 141-160.

Ranganathan, R., Chauhan, Y.S., Flower, D.J., Robertson, M.J., Sanetra, C., Silim, S., 2001. Predicting growth and development of pigeonpea: leaf area development. Field Crops Res. 69, $163-172$.

Roberts, E.H., Summerfield, R.J., 1987. Measurement and production of flowering in annual crops. In: Atherton, J.G. (Ed.), Manipulation of Flowering. Butterworths, London, pp. 17-50.

Saxena, K.B., Sharma, D., 1990. Pigeonpea: genetics. In: Nene, Y.L., Hall, S.D., Sheila, V.K. (Eds.), The Pigeonpea. CAB International, Wallingford, pp. 137-158.

Sharma, D., Green, J.M., 1980. Pigeonpea. In: Fehr, W.R., Hadley, H.H. (Eds.), Hybridization of Crop plants. American Society of Agronomy, Madison, WI, p. 471.

Sharma, D., Reddy, L.J., Green, J.M., Jain, K.C., 1981. International adaptation of pigeonpeas. In: Proceedings of the
International Workshop on Pigeonpeas, Vol. 1, December 1519, 1980, ICRISAT Center, India. ICRISAT, Patancheru, AP, India, pp. 77-81.

Singh, H.P., Saxena, M.C., 1981. Effect of date of planting on the time of flowering in greengram, blackgram, cowpea and pigeonpea. In: Proceedings of the International Workshop on Pigeonpeas, Vol. 1, December 15-19, 1980, ICRISAT Center, India. ICRISAT, Patancheru, AP, India, pp. 165-174.

Summerfield, R.J., Roberts, E.H., 1985. Cajanus cajan. In: Halevy, A.H. (Ed.), CRC Handbook of Flowering, Vol. 1. CRC Press, Boca Raton, FL, pp. 83-91.

Summerfield, R.J., Lawn, R.J., Ellis, R.H., Roberts, E.H., Shanmugasundaram, S., Chay, P.M., Brouwer, J.B., Rose, J.L., Yeates, S.J., Sandover, S., 1995. Towards the reliable prediction of time to flowering in six annual crops. The University of Reading, Reading, UK, 127 pp.

Troedson, R.J., Wallis, E.S., Laxman S., 1990. Pigeonpea: adaptation. In: Nene, Y.L., Hall, S.D., Sheila, V.K. (Eds.), The Pigeonpea. CAB International, Wallingford, pp. 159-177.

Turnbull, L.V., 1986. The role of photoperiod and temperature in early vegetative growth and floral development in selected lines of pigeonpea (Cajanus cajan (L.) Millsp.). Ph.D. Thesis. University of Queensland, Australia, 309 pp.

Turnbull, L.V., Whiteman, P.C., Byth, D.E., 1981. The influence of temperature and photoperiod on floral development of early flowering pigeonpea. In: Proceedings of the International Workshop on Pigeonpeas, Vol. 1, December 15-19, 1980, ICRISAT Center, India. ICRISAT, Patancheru, A P, India, pp. 217-223. 